\title{
Erratum to: A systematic review of orofacial pain in patients receiving cancer therapy
}

\author{
Joel B. Epstein • Catherine Hong • Richard M. Logan • Andrei Barasch • \\ Sharon M. Gordon • Loree Oberle-Edwards • Deborah McGuire • Joel J. Napenas • \\ Linda S. Elting • Fred K. L. Spijkervet • Michael T. Brennan
}

Published online: 4 November 2010

(C) Springer-Verlag 2010

\section{Erratum to: Support Care Cancer \\ DOI 10.1007/s00520-010-0897-7}

Unfortunately, the name of an author is misspelled. It should read Loree Oberle-Edwards.

The online version of the original article can be found at http://dx.doi. org/10.1007/s00520-010-0897-7.

\section{J. B. Epstein $(\bowtie)$}

Department Oral Medicine and Diagnostic Sciences,

Otolaryngology and Head and Neck Surgery and Cancer Center,

MC 838, University of Illinois,

Chicago, IL 60612, USA

e-mail: jepstein@uic.edu

C. Hong $\cdot$ J. J. Napenas $\cdot$ M. T. Brennan

Department of Oral Medicine, Carolinas Medical Center,

P. O. Box 32861, Charlotte, NC 28232, USA

C. Hong

e-mail: catherine.hong@carolinas.org

J. J. Napenas

e-mail: joel.napenas@carolinas.org

M. T. Brennan

e-mail: mike.brennan@carolinas.org

\section{R. M. Logan}

Oral Pathology, School of Dentistry,

Faculty of Health Sciences, Consultant Oral Pathologist,

Division of Surgical Pathology,

SA Pathology, The University of Adelaide,

Adelaide, Australia

e-mail: richard.logan@adelaide.edu.au

\section{A. Barasch}

Department of General Dental Sciences,

University of Alabama at Birmingham,

SDB 111,

Birmingham, AL 35294-0007, USA

e-mail: abarasch@uab.edu
S. M. Gordon

University of Maryland,

650W Baltimore St.,

Baltimore, MD, USA

e-mail: sgordon@umaryland.edu

L. Oberle-Edwards

Scripps Center for Dental Care,

9850 Genesee Ave,

La Jolla, CA 92037, USA

e-mail: loree@empowerpeople.com

D. McGuire

University of Maryland School of Nursing, Program in Oncology,

University of Maryland Marlene and Stewart Greenebaum

Cancer Center,

655 West Lombard Street, 325B,

Baltimore, MD 21201, USA

e-mail: dmcguire@son.umaryland.edu

L. S. Elting

Department of Biostatistics,

The University of Texas M.D. Anderson Cancer Center,

1515 Holcombe Blvd,

Houston, TX 77030, USA

e-mail: lelting@mdanderson.org

\section{F. K. L. Spijkervet}

Department of Oral \& Maxillofacial Surgery,

University Medical Center Groningen, University of Groningen,

Hanzeplein 1,

9700 RG Groningen, The Netherlands

e-mail: f.k.l.spijkervet@kchir.umcg.nl 